\title{
Feasibility and benefits of group based exercise in residential aged care adults: a pilot study for the GrACE programme
}

Samantha Fien, Justin William Leslie Keogh, Timothy Henwood, Mike Climstein

The objective of the study was to examine the feasibility and benefits of a group resistance training exercise programme for improving muscle function in institutionalised older adults. A feasibility and acceptability study was designed for a residential aged care facility, based on the Gold Coast, Australia. Thirty-seven adults, mean age $86.8 \pm 6.1$ years (30 females) living in a residential aged care facility. Participants were allocated into an exercise $(n=20)$ or control $(n=17)$ group. The exercise group, the GrACE programme, performed 12 weeks of twice weekly resistance exercises. Feasibility was measured via recruitment rate, measurement (physiological and surveys) completion rate, loss-to-followup, exercise session adherence, adverse events, and ratings of burden and acceptability. Muscle function was assessed using gait speed, sit-to-stand and handgrip strength assessments. All intervention participants completed pre- and post-assessments, and the exercise intervention, with $85 \%$ ( $n=17$ ) of the group attending $\geq 18$ of the 24 sessions and $15 \%(n=3)$ attending all sessions. Acceptability was $100 \%$ with exercise participants and staff who had been involved with the programme strongly agreeing that the participants "Benefited from the programme". There were no adverse events reported by any participants during the exercise sessions. When compared to the control group, the exercise group experienced significant improvements in gait speed $(F(4.078)=8.265, p=$ $0.007)$, sit to stand performance $(F(3.24)=11.033, p=0.002)$ and handgrip strength $(F(3.697)=26.359, p<0.001)$. Resistance training via the GrACE programme is feasible, safe and significantly improves gait speed, sit-to-stand performance and handgrip strength in residential aged care adults. 
1 Feasibility and acceptability of group based exercise in residential aged care

2 adults: a pilot study for the GrACE programme

3 Samantha Fien ${ }^{1}$, Timothy Henwood ${ }^{2,1}$, Mike Climstein ${ }^{3}$ Justin William Leslie Keogh ${ }^{1,4,5}$

$4 \quad{ }^{1}$ Faculty of Health Science and Medicine, Bond University, Robina, Australia

$5 \quad{ }^{2}$ School of Human Movement \& Nutrition Sciences, The University of Queensland,

6 Brisbane, Australia

$7 \quad{ }^{3}$ Exercise, Health and Performance Faculty Research Group, The University of Sydney,

8 Australia

$9 \quad{ }^{4}$ Human Potential Centre, AUT University, Auckland, New Zealand

$10{ }^{5}$ Cluster for Health Improvement, Faculty of Science, Health, Education and

11 Engineering, University of the Sunshine Coast, Sippy Downs, Australia

\section{Corresponding Author}

13 Samantha Fien

14 Faculty of Health Science and Medicine,

15 Bond University,

16 Robina, Australia

$17 \quad 4229$

18 Ph. +61755954487

19 Fax: +6175595 3524

20 E. samantha.fien@student.bond.edu.au 


\section{Introduction}

22 Ageing can lead to an impaired physical function, mobility and reduction in quality of life

23 (Krist et al. 2013). A decrease in mobility may prompt a vicious cycle of sedentary

24 behaviours, reduced physical activity and deconditioning, with residential aged care

25 (RAC) adults shown to be more sedentary than their community-dwelling counterparts

26 (Reid et al. 2013). The mobility decline may reflect the emergence of sarcopenia, which

27 is defined as the progressive and generalised loss of skeletal muscle mass and 28 subsequent muscle function (muscle strength and physical performance) associated

29 with the ageing process (Cruz-Jentoft et al. 2010). The preferred sarcopenic measure for 30 physical performance in older adults is gait speed, which is also considered a primary 31 precursor to age-related adverse events including disability, cognitive impairment, falls, 32 mortality, institutionalisation and hospitalisation (Abellan van Kan et al. 2009; Cruz33 Jentoft et al. 2010; Peel et al. 2013). The threshold to be considered as having normal or

34 above habitual gait speeds is $0.8 \mathrm{~m} / \mathrm{s}$ (Kuys et al. 2014), a value almost identical to the $350.82 \mathrm{~m} / \mathrm{s}$ cut-off proposed as being predictive of death within two years for older men 36 (Stanaway et al. 2011).

37 A meta-analysis of 2,888 long-term ambulant RAC residents reported a mean habitual 38 gait speed of $0.48 \mathrm{~m} / \mathrm{s}$ (95\% confidence interval $(\mathrm{Cl})$ 0.40-0.55) (Kuys et al. 2014). 39 However, it was cautioned that the true mean gait speed of RAC adults may be even 40 less than $0.48 \mathrm{~m} / \mathrm{s}$ as many of the reviewed studies utilised non-randomly selected 41 samples, meaning the participants were likely to be more mobile than those who did not 42 consent to participate. Consistent with such a view, a recent study of 102 randomly 43 selected RAC residents reported a mean gait speed of $0.37 \mathrm{~m} / \mathrm{s}$ (Keogh et al. 2015). 44 The widespread low gait speed documented for RAC adults and the link between low 
45 gait speed and many adverse age-related effects suggests that further research needs

46 to be conducted to examine feasible and efficacious approaches to improving or at least

47 offsetting the expected annual decline in gait speed of $0.03-0.05 \mathrm{~m} / \mathrm{s}$ per year (Auyeung

48 et al. 2014; Onder et al. 2002).

49 Two recent reviews have examined the potential for exercise, and specifically 50 progressive resistance training (e.g. strength) and weight bearing exercise (e.g. balance

51 and mobility) to improve many aspects of muscle function including gait speed in 52 RAC/frail older adults (Chou et al. 2012; Valenzuela 2012). In their meta-analysis of 225 53 participants across four studies, Chou et al. (2012) reported that exercise produced a 54 significant $0.07 \mathrm{~m} / \mathrm{s}(\mathrm{Cl} 0.02-0.11)$ increase in gait speed compared to the control group $55(-6 \%$ change). However, a limitation of this literature is that the implementation of these 56 exercise programmes in RAC is still relatively uncommon. This lack of translation may 57 reflect the many barriers to the sustainability of resistance combined with weight bearing 58 training programmes in RAC (Federal Interagency Forum on Aging-Related Statistics. 59 2004) and to our knowledge, a complete lack of research quantifying the feasibility of 60 this form of exercise in this setting.

61 A possible exception is an exercise programme, which was targeted at respite care older 62 adults in Australia (Henwood et al. 2013). Older adults accessing respite care are unable 63 to completely care for themselves due to the adverse effects of ageing, chronic disease, 64 physical and/or cognitive disability and are at increased risk of entry into RAC. These 65 individuals typically access respite day care for several hours per day for one or more 66 days per week to allow their carer the opportunity to attend to other everyday activities 67 or to have a break from their caregiving responsibilities. An analysis of the exercise 
68 programme demonstrated a high feasibility for translation into an ongoing respite day

69 care centre and that two hours of participation per week for 20 weeks significantly

70 improved functional capacity and balance among participants (Henwood et al. 2013).

71 While this programme was feasible and effective in a disabled community-dwelling

72 population, it is yet to be trialled amongst RAC adults. Given the demonstrated uptake of

73 this exercise programme by a low functioning older adult population at risk of entry into

74 RAC, it is hypothesised that the Group Aged Care Exercise (GrACE) programme will

75 exhibit similar levels of feasibility and benefits in RAC adults (Henwood et al. 2013).

76 The primary aim of this study was to determine the feasibility of the GrACE programme

77 in RAC, with the secondary objective of measuring the programme benefits on gait

78 speed, sit to stand and handgrip strength.

79 Material and methods

80 Participants

81 Participants were included if they were:

82 i. Aged 65 years and over,

83 ii. Residing in a RAC,

84 iii. Able to walk with a walker and/or walking stick or could self-ambulate and,

85 iv. Could provide informed consent.

86 The exclusion criteria included:

87 i. End-stage terminal and/or life expectancy $<6$-months (ethical reasons),

88 ii. Two person transfer or unable to self-ambulate (due to increased falls risk),

89 iii. Unable to communicate or follow instructions (personal needs beyond the scope

90 of this project),

91 iv. Insufficient cognitive function to provide informed consent and,

92 v. Dangerous behaviours that would endanger the client or research staff. 


\section{Study Design and Recruitment}

94 This study compared the delivery feasibility and outcomes of a 12-week combined 95 resistance and weight bearing exercise programme, which we named the GrACE 96 programme. Participant recruitment and assessment occurred over a five-month period. 97 The flow of recruitment to assessment is represented in Figure 1.

98 Insert figure 1 about here

99 The RAC was approached about participation via email and telephone follow-up.

100 Potential participants were identified at a meeting with the facility Service Manager.

101 Participants were screened via the inclusion criteria at the meeting with the Service

102 Manager and a Registered Nurse, whom also deemed who would be able to perform the 103 exercises due to the inclusion and exclusion criteria. The Service Manager and a

104 Registered Nurse created two lists from the eligible participants, one that contained the

105 names of residents who could be recruited for the exercise group and one for the 106 recruitment of the control group. This group allocation was based on the location of their

107 bedroom with respect to the training room, as the Service Manager and a Registered 108 Nurse felt that only participants who resided on the same level as the exercise room 109 were likely to join and adhere to the GrACE programme. As we wished to get some idea 110 on the number of participants who would enrol in such an exercise program, the sample

111 obtained in the current study reflected the maximum number of participants who were

112 eligible and provided their informed consent to participate. The final sample obtained 113 was a convenience sample from one RAC facility. Following an explanation of the 114 procedures, purposes, benefits and associated risks of the study, participants had the

115 opportunity to ask questions. A total of 37 older RAC adults (86.8 \pm 6.1 years, range $72-$ 
11699 years, 30 females) provided written informed consent for the study. The exercise

117 group contained 20 participants (86.9 \pm 5.7 years, range 72-97 years, 15 females) and

118 the control group 17 participants (86.3 \pm 6.6 years, range 75-99 years, 15 females).

119 Ethical approval to conduct this study was attained from Bond University's Human Ethics

120 Research Committee (RO 1823). The protocol for this trial was published at Clinical Trial

121 Registry ID NCT02640963.

\section{Intervention: the GrACE programme}

123 Previous work by our group trialed a successful exercise programme in respite day care

124 that could promise benefits to those in RAC (Henwood et al. 2013). The GrACE

125 programme's full outline is available in Appendix 1. In brief, the programme included a

126 number of targeted weight-bearing exercises (using body weight and dumbbells) and a

127 range of seated, non-resisted upper- and lower-body dynamic and reaching movements.

128 While developed for respite care older adults, the programme was slightly modified for

129 the RAC setting; initially using reduced range of motion and resistance, and an extended

130 conditioning/familiarisation phase. The conditioning phase lasted for three weeks in

131 which technique was emphasised without using any weights or additional resistance.

132 The focus of this technique of the conditioning phase was to develop the correct

133 technique and minimise the potential for any delayed onset muscle soreness or adverse

134 effects. After concluding the conditioning phase, participants were able to use light

135 dumbbells (often starting with $0.5 \mathrm{~kg}$ ) increasing to heavier dumbbells (up to $4 \mathrm{~kg}$ ) with

136 their increasing capacity over the course of the programme.

137 Participants performed the exercises twice per week for 12 weeks, with an average of

13815 of the 20 participating residents attending each exercise class. Training sessions

139 lasted approximately 45 minutes, were separated by at least 48 hours and were 
140 delivered by an allied health professional experienced working with RAC adults. The

141 sessions were conducted in the communal dining room, where the furniture was moved

142 around prior and post training. The dining room was selected as the facility in which the

143 exercise programme was performed had three levels, with the dining room located on

144 the level having the highest number of residents. The allied health professional (exercise

145 physiologist) was not blinded to the allocation of participants as they collected both pre

146 and post outcomes for the study as well as conducting the exercise programme. The

147 exercise physiologist was experienced working with community dwelling older adults,

148 but received additional training prior to the project delivery via the respite community-

149 training package used in a previous study (Henwood et al. 2013) and by RAC facility

150 staff on issues relevant to working with RAC residents.

\section{Control Group}

152 All subjects assigned to the control group were given the option to engage in other

153 activities that were offered by the facility during the 12-week intervention period.

154 Activities were conducted either in their fitness room or communal areas, and included

155 Zumba Gold, aerobic exercise and walking. These sessions lasted for 30 to 45 minutes

156 and conducted by their facility's leisure staff. However, no specific resistance exercises

157 were offered in these activities.

\section{Data Collection}

159 Reasons for refusal (non-consent) to participate were recorded (Henwood et al. 2014).

160 All muscle function outcome measures in this study have been previously validated for

161 use with older adults, and their protocols reported elsewhere (Henwood et al. 2013;

162 Sterke et al. 2012). Assessments were completed one-on-one with each participant,

163 assessing muscle function as well as a range of demographic characteristics, which are 
164 important in describing the sample. During muscle function measures assessments,

165 participants were encouraged to rest as needed and given verbal support and

166 encouragement to reduce any potential burden to the participant.

\section{Measures}

168 Feasibility Outcomes

169 The assessment of feasibility was defined by recruitment rate, measurement

170 (physiological and surveys) completion rate, loss-to-follow-up, exercise session

171 adherence, acceptability and adverse events (Bower et al. 2014; Peddle-McIntyre et al.

172 2012; Suttanon et al. 2013). Recruitment rate was defined as the number of residents

173 recruited from those invited. Measurement completion rate was defined as the number

174 of participants able to complete each outcome measure at baseline and follow-up. Loss

175 to follow-up was defined as participants who withdrew or dropped out and did not

176 consent to a follow up assessment. Exercise session adherence was measured by the

177 number of sessions attended out of the maximum 24 sessions. Consistent with previous

178 exercise studies involving low functioning older adults (Bossers et al. 2014; Bower et al.

179 2014; Henwood et al. 2013), the proportion of participants who completed $75 \%$ and

$180100 \%$ of the required 24 sessions was recorded. Acceptability was measured via a

181 programme satisfaction survey completed post-training that assessed the burden of

182 training and testing, as well as how participants felt about the trial. Questions included:

183 - "Prior to commencing the exercise programme did you have any concern(s) with

184 the GrACE programme?",

185 - "Did you enjoy participating in the GrACE programme?",

186 - "Do you believe the GrACE programme was well organised?",

187 - "Whilst participating in the GrACE programme do you believe that the programme

188 impeded on your daily routine?",

189 - "Would you be happy to continue participating in the GrACE programme or

190 something similar?" and 
191 - "Overall, would you rate your current physical condition to be better than before

192 you started the GrACE programme?"

193 Answers to the acceptability questions were scored on a five-point Likert Scale $(1=$

194 strongly agree, agree, neither, disagree or 5 = strongly disagree).

195 Adverse events were defined as incidents in which harm or damage resulted to a 196 participant and included, but were not limited to, falls and fall-related injuries, 197 musculoskeletal or cardiovascular incidents and problems with medication and medical 198 devices (Australian Government. 2014). These adverse events were recorded via the 199 facility's records. The exercise group also received a diary to record if they had any 200 muscle soreness or complaints about the exercise class. These diaries were returned to 201 the instructor at the end of each week. The exercise instructor also verbally confirmed 202 the information contained in these diaries with each of the exercise group participants at 203 the end of each week.

204 Muscle Function Measures Outcomes

205 Gait Speed

206 Gait speed was recorded via the GaitMat II system (Manufacturer is EQInc; Model is 207 GaitMat II), which required participants to walk across a level pressure mat system 3.66 $208 \mathrm{~m}$ (11.91 ft.) long (McDonough et al. 2001). Participants completed the trials at their 209 preferred (habitual) walking (gait) speed. The following instructions were given, "Walk

210 towards the end of the room at a pace that is comfortable for you". Participants were 211 allowed to walk in their own footwear. All measures were initiated from a standing start 2 $212 \mathrm{~m}$ (6.56 ft.) from the GaitMat II platform as suggested by Kressig and Beauchet (2004) 213 to reduce the effect that acceleration may have on gait speed. The average gait speed $214(\mathrm{~m} / \mathrm{s})$ from three attempts was used for data analysis. Participants were allowed as 
215 much rest as required between attempts, with rest periods typically being up to 1 minute.

\section{Handgrip strength}

217 Upper body muscle function was measured by isometric handgrip strength. When

218 performing the handgrip strength assessments, participants were seated, instructed to

219 keep their elbow at $90^{\circ}$ and asked to squeeze a handgrip dynamometer (Sammons

220 Preston Roylan, Bolingbrook, IL) to their maximum ability for a period of up to five

221 seconds (Mathiowetz 2002). Three trials were performed with the subject's dominant

222 hand with one-minute rest between trials and the best result used for analysis (Roberts

223 et al. 2011).

\section{Sit to stand performance}

225 The sit-to-stand measure was performed to assess lower body muscle function of the 226 participants. In the sit-to-stand measure, participants sat and stood to their full standing 227 position from a $43 \mathrm{~cm}$ high chair as many times as possible in 30 seconds whilst 228 keeping their arms crossed against their chest (Millor et al. 2013). Timing commenced 229 when the assessor gave the command "go".

\section{Participant demographics}

231 All participants were assessed for Body Mass Index (BMI), body fat percentage (\%) and 232 cognitive status at pre-and post-testing. Body Mass Index was calculated based on 233 body mass $(\mathrm{kg})$ divided by the square of height $\left(\mathrm{m}^{2}\right)$. Body fat was estimated via

234 Bioelectrical Impedance Analysis (BIA, Maltron BF-906 body fat analyser) (Senior et al. 235 2015). The BIA required participants to have two electrode stickers placed on their hand 236 as well as two on their foot whilst in the supine position. The flow of electrical signals 237 was measured through fat, lean tissue and water, which was then applied to a database 
238 of algorithms revealing the whole body analysis (Chien et al. 2008). Cognitive status

239 was quantified via the Mini Cog (Borson et al. 2000). The Mini Cog was scored out of

240 three words that are recalled after drawing the face of a clock on a piece of paper to

241 read ten minutes after eleven o'clock, with scores $>1-2$ recalled words and abnormal

242 clock drawing, indicative of cognitive impairment (Borson et al. 2000).

\section{Statistical Analysis}

244 Descriptive statistics were calculated to describe the baseline characteristics and

245 feasibility results, with all continuous variables presented as mean and standard 246 deviation $( \pm S D)$, and for categorical variables as the total number and percentage (\%) of

247 responses. In circumstances where participants were unable to complete a physical 248 measure, they were given the lowest score, generally zero. All data were initially 249 checked for normality prior to analysis by investigating homogeneity of regression 250 slopes, scatterplots for linearity, kurtosis, skewness and Levene's test of equality of error

251 variances. Baseline characteristics of the two groups were compared using ANCOVA 252 and chi-square analysis for continuous and categorical variables, respectively. A one253 way ANCOVA was performed to assess the between-group changes in gait speed, 254 handgrip strength and sit to stand performance. SPSS (version 20) was used for data 255 analysis; statistical significance was set at $\mathrm{p} \leq 0.05$ a priori.

\section{Results}

257 Descriptive characteristics of the sample, provided in Table 1, showed no significant 258 difference between groups at baseline. Of the 62 individuals put forward for participation 259 by the RAC Service Manager, 47 were found to be eligible and 37 consented to 260 involvement. At follow-up, 3 participants in the control group had passed away, resulting 261 from falls complications $(n=1)$ and pre-existing heart disease $(n=2)$. Apart from these 
262 three deaths, the study experienced a $100 \%$ retention rate of surviving participants and 263 final analysis was conducted on 34 individuals (20 intervention and 14 control). 264 Seventeen (85\%) participants in the exercise group attended 18 or more exercise 265 sessions, with $3(15 \%)$ of these 17 participants attending all 24 training sessions.

266 Insert Table 1 about here

267 Participant responses to the exercise programme questionnaire, measured by the Likert 268 scale questions are summarised in Table 2. Acceptability of the programme was very 269 high with $100 \%$ of exercise participants and staff who had been involved with the 270 programme (i.e. nurses who helped bring the residents from their rooms to the GrACE 271 programme or observed the class from the nurses' station) strongly agreeing that the 272 participants "Benefited from the GrACE programme" and "Happy to continue 273 participating". Refer to Appendix 2 to see the full responses to the open-ended 274 questions. With respect to diary completion, all diaries were returned with five partially 275 completed (ranging from $50 \%$ to $80 \%$ ) and 15 fully completed. There were no adverse 276 events reported by any participants during the exercise sessions.

277 Insert Table 2 about here

278 The exercise group had significantly greater improvements in habitual gait speed $279(F(4.078)=8.265, p=0.007)$, sit to stand performance $(F(3.24)=11.033, p=0.002)$ and 280 handgrip strength $(F(3.697)=26.359, p<0.001)$ when compared to the control group. 281 Pre- and post-intervention muscle function measures data are presented in Table 3. 
282 Insert Table 3 about here

\section{Discussion}

284 This study demonstrated a combined weight bearing and resistance training exercise

285 programme which we called the GrACE programme, designed and tested in community-

286 dwelling respite day care older adults, is feasible, safe and effective in improving gait

287 speed, sit to stand performance and handgrip strength in RAC adults. Findings from this

288 study may assist RAC providers and care staff to develop and implement feasible, safe

289 and effective exercise programmes for their residents.

290 The recruitment rates for this exercise trial appeared similar or better than other similar

291 trials in respite care, hospital inpatient or RAC populations (Bower et al. 2014; Henwood

292 et al. 2013; Peddle-Mclntyre et al. 2012; Suttanon et al. 2013). Sixty-two of the 151

293 residents were identified by the service manager as being potentially eligible for the

294 study, a proportion equating to approximately $40 \%$ of total population of the RAC facility.

295 The other 89 RAC residents were deemed ineligible due to the following: being in a

296 wheelchair or restricted to bed duties, not being able to follow simple instructions, lack of

297 attention or unpredictable behaviour. Interesting to note that some residents $(n=10)$

298 refused to participate due to fear of change in their schedule, fear of never doing

299 resistance training before and not wanting to try and after being in the RAC facility for

300 over five years had declared they weren't doing exercise anymore. Suggested ideas to

301 overcome this was through word of mouth via residents to other residents, especially at

302 communal times such as breakfast, where the residents remind each other of exercise 303 class. 
304 Of the 62 residents identified by the service manager as being eligible to participate, 37

$305(60 \%)$ provided informed consent and were placed into either the exercise or control 306 groups. While a recruitment rate of $60 \%$ of the eligible participants may appear 307 relatively low, this value appeared comparable (Henwood et al. 2015) or slightly higher 308 (Alvarez-Barbosa et al. 2014; Bossers et al. 2014; Sievanen et al. 2014) than previous 309 exercise trials in RAC. The reason provided by the $25(40 \%)$ potentially eligible 310 participants who declined to participate included: not being interested in the study or 311 exercise programme, lack of time: didn't want to commit to the 12 weeks, didn't want to 312 try something different/that was out of the normal routine and were happy with their 313 current lifestyle. The reasons reported by the potential participants who declined 314 participation in this project should be taken into account by future researchers 315 considering conducting RAC exercise RCTs if they wish to ensure maximum participant 316 recruitment and statistical power of the resulting analyses.

317 For the 20 participants who were enrolled into the GrACE programme, adherence rates 318 were high with $85 \%$ of the participants attending at least $18(75 \%)$ of the required 24 319 exercise classes. This relatively high attendance rate appeared similar (Alvarez-Barbosa 320 et al. 2014; Bossers et al. 2014; Sievanen et al. 2014) or greater than (Hassan et al. in 321 press; Henwood et al. 2015) previous feasibility exercise studies involving RAC older 322 adults. Such results suggest that many exercise class options (if offered) may be well 323 attended by residents of RAC facilities. The acceptability of the programme was further 324 assessed by using a five-point Likert scale questionnaire that focused on the 325 participants' perceptions of the exercise sessions. All exercise participants strongly 326 agreeing that they obtained substantial benefits from their participation and that they 327 wished to continue being involved in the programme. These results are consistent with 
328 previous studies reporting high acceptability of RAC exercise participation (Alvarez-

329 Barbosa et al. 2014; Bossers et al. 2014; Henwood et al. 2015; Sievanen et al. 2014). In 330 contrast however, our study supports the feasibility of an in-centre delivery using

331 targeted supervision and inexpensive equipment, where previous work has employed 332 more complicated deliveries. Specifically, Bossers et al. (2014) delivered individualised, 333 supervised walking and strength training programmes five days per week, Sievanen et 334 al. (2014) and Alvarez-Barbosa et al. (2014) delivered their interventions using relatively 335 expensive whole body vibration devices, Hassan et al. (in press) used expensive 336 resistance training machines and Henwood et al. (2015) trialled aquatic exercise that 337 required participants to be transported to and from a community pool and change in and 338 out of swimming attire. Our study required only one qualified trainer; the exercises were 339 conducted at the RAC facility so there was no transport needed and delivery was not 340 affected by busy times or school holidays such as experienced by Henwood et al. 341 (2015). Further, our study didn't need to have a personalised exercise programme 342 developed for each individual resident or require the purchase and storage of expensive 343 equipment (Alvarez-Barbosa et al. 2014; Hassan et al. in press; Sievanen et al. 2014). 344 The acceptability of the programme was further demonstrated by the lack of any 345 adverse effects reported within the exercise group. This lack of adverse effects is again 346 consistent with the literature on a variety of exercise programmes for RAC residents 347 (Alvarez-Barbosa et al. 2014; Bossers et al. 2014; Hassan et al. in press; Henwood et 348 al. 2015; Sievanen et al. 2014). Therefore, our study further supports the safety of 349 supervised exercise in this population, and demonstrates that the perception held by 350 some care staff that exercise is a dangerous for RAC residents is not based on the 351 current peer-reviewed evidence. 
352 It must however be acknowledged that although the GrACE programme was found to be

353 feasible for those who participated in this study, this amounted to only $\sim 25 \%$ of the 354 population of the RAC facility. Collectively, the results of this study suggest that further 355 feasibility trials may need to target RAC residents who were ineligible for this study 356 (Gibbs et al. 2015) and also examine some of the issues influencing recruitment rates 357 from those who were eligible to participate (Kalinowski et al. 2012).

358 While the primary focus of this study was to demonstrate feasibility and acceptability of 359 the GrACE programme in RAC, we were also interested in further quantifying the 360 benefits of exercise in this population as such data may inform future RCTs in this area. 361 Significant between-group differences were reported for gait speed, sit to stand 362 performance and handgrip strength, all of which favoured the exercise over the control 363 group. Such results are impressive due to the relative simplicity of the GrACE 364 programme performed in the current study and the importance of these outcome 365 measures for older adults, particularly those living in RAC who wish to maintain their 366 health and independence.

367 The significant between group effect for gait speed was a promising finding, with the 368 relative $0.07 \mathrm{~m} / \mathrm{s}$ improvement in gait speed for the exercise group was identical to the 369 results of a recent meta-analysis involving exercise for RAC residents (Chou et al. 370 2012). However results of the within-group analysis indicated that the exercise group 371 experienced an increase in gait speed of $0.03 \mathrm{~m} / \mathrm{s}(\sim 5 \%)$, whereas the control group 372 experienced a decline of $0.04 \mathrm{~m} / \mathrm{s}(\sim 6 \%)$. As the control group's decline of $0.04 \mathrm{~m} / \mathrm{s}$ was 373 consistent with the expected annual decline of $0.03-0.05 \mathrm{~m} / \mathrm{s}$ per year for older adults 374 (Auyeung et al. 2014; Onder et al. 2002), the GrACE programme appears able to 375 maintain or perhaps slightly increase gait speed in this population. 
376 The significantly greater improvement in sit-to-stand performance for the exercise group 377 was of considerable interest, with none of the residents being able to perform the sit-to-

378 stand with their hands on the chest during baseline assessments. The ability to safely 379 rise from a chair and sit down is a prerequisite for maintaining Activities of Daily Living 380 (ADL) function (Zijlstra et al. 2012). Specifically, older adults who are unable to perform 381 the sit to stand are considered below the capacity for independence and at risk of 382 accelerated physical deterioration associated to extended sedentary behaviours (Zijlstra 383 et al. 2012). The RAC participants' lack of leg strength (as demonstrated by their initial 384 inability to perform even one sit to stand) was consistent with previous research that 385 observed over $70 \%$ of RAC adults were unable to rise from a chair without assistance 386 (Sabol et al. 2011).

387 The exercise group's significantly greater improvement in handgrip strength was also 388 considered important, as lower handgrip strengths have predicted an accelerated 389 decline in ADL disability and cognition as well as functional limitation and physical 390 disability in older adults (Bohannon 2007; Hairi et al. 2010; Taekema et al. 2010). The 391 exercise-related increase in handgrip strength was also consistent with a previous 392 exercise study in RAC (Justine et al. 2012).

\section{Study Limitations}

394 There were several limitations in the current study. We acknowledge that 37 participants 395 assessed represented a recruitment rate of only $59.6 \%$ of the participants initially 396 thought to be eligible for the study and only about $25 \%$ of the facility's population.

397 However, this rate of uptake is not uncommon in RAC, nor is the strict eligibility criteria 
398 imposed or participant safety reasons in exercise intervention Therefore, caution is

399 warranted if considering this GrACE programme feasibility across all RAC populations. It 400 should also be noted that there was a risk of bias with the same allied health practitioner

401 conducting the outcome measures and supervising the exercise programme. Future 402 RCT should address this limitation by blinding the assessor to the participants' group 403 allocation. The significant improvements observed in the present study for gait speed, sit 404 to stand performance and handgrip strength also need to be replicated in RCTs due to 405 the lack of a controlled study design and attention matching of the participants of each 406 group.

\section{Conclusion}

408 The GrACE programme, consisting of progressive weight bearing combined with 409 resistance training, was shown to be feasible, safe and effective in improving muscle 410 function in RAC residents. Improved muscle function measurements are valuable client 411 outcomes, and may have significant cost saving benefits to the RAC setting, as 412 increased muscle function could reduce the RAC residents' degree of disability, care 413 needs and risk of falls (Chou et al. 2012). This work has direct measurable benefits for 414 RAC residents, staff and providers and other health professionals working with older 415 adults. Our findings addressed a number of previously unanswered and understudied 416 questions in relation to the feasibility, safety and benefits of exercise classes that could 417 be offered by RAC facilities to their residents. By having a greater understanding of 418 these issues, RAC providers can better target interventions (e.g. exercise for 419 maintaining gait speed or to reduce falls risk) to their residents. We would therefore 420 encourage other RAC providers to strongly consider implementing similar programmes. 


\section{Clinical messages}

422

423

424

425

426

427

428

429

430

431

435

436

438

- Progressive resistance and weight bearing training, as performed in the GrACE programme, is feasible and safe for RAC residents.

- Progressive resistance and weight bearing training may significantly improve gait speed, sit-to-stand performance and handgrip strength in RAC residents.

\section{Acknowledgement}

We would like to thank the management, staff and residents of the RAC for their assistance and participation in this project.

\section{References}

Abellan van Kan G, Rolland Y, Andrieu S, Bauer J, Beauchet O, Bonnefoy M, Cesari M, Donini LM, Gillette Guyonnet S, Inzitari M, Nourhashemi F, Onder G, Ritz P, Salva A, Visser M, and Vellas B. 2009. Gait speed at usual pace as a predictor of adverse outcomes in community-dwelling older people an International Academy on Nutrition and Aging (IANA) Task Force. Journal of Nutrition, Health and Aging $13: 881-889$

Alvarez-Barbosa F, del Pozo-Cruz J, del Pozo-Cruz B, Alfonso-Rosa RM, Rogers ME, and Zhang Y. 2014. Effects of supervosed whole body vibration exercise on fall risk factors, functional dependence and health-related quality of life in nursing home residents aged 80+. Maturitas 79:456-463. 
440 Australian Government. 2014. Aged care in Australia: Part I - Policy, demand and 441 funding CEPAR research brief.

442 Auyeung TW, Lee SWJ, Leung J, Kwok T, and J W. 2014. Age-associated decline of muscle mass, grip strength and gait speed: A 4-year longitudinal study of 3018 community-dwelling older Chinese. Geriatrics and Gerontology International $14: 76-84$.

Bohannon RW, Bear-Lehman, J., Desrosiers, J., Massy-Westropp, N., Mathiowetz, V. 2007. Average grip strength: a meta analysis of data obtained with a Jamar dynamometer from inidividuals 75 years or more of age. Journal of Geriatric Physical Therapy 30:28-30.

Borson S, Scanlan J, Brush M, Vitallano P, and Dokmark A. 2000. The Mini-Cog: a cognitive vital signs measure for dementia screening in multi-lingual elderly. International Journal of Geriatric Psychiatry 15:1021-1027.

Bossers WJR, Scherder EJA, Boersma F, Hortobagyi T, van der Woude LHV, and van Heuvelen MJG. 2014. Feasibility of a combined aerobic and strength training program and its effects on cognitive and physical function in institutionalized dementia patients. a pilot study PLoS One 9:e97577. the Nintendo Wii for balance training post-stroke: a phase II randomized controlled trial in an inpatient setting Clinical Rehabilitation 28:912-923 bioelectrical impedance analysis prediction equation in community-dwelling elderly people in taiwan Journal of the American Geriatrics Society 56:1710-1715. 
463 Chou CH, Hwang CL, and Wu YT. 2012. Effect of exercise on physical function, daily 464 activities, and quality of life in the frail older adults: a meta analysis. Archives of $465 \quad$ Physical Medicine and Rehabilitation 93:237-244.

466 Cruz-Jentoft AJ, Baeyens JP, Bauer JM, Boirie Y, Cederholm T, Landi F, Martin FC, 467 Michel JP, Rolland Y, Schneider SM, Topinkova E, and Vandewoude M. 2010.

468 Sarcopenia: European consensus on definition and diagnosis: Report of the 469 European Working Group on Sarcopenia in Older People. Age and Ageing $470 \quad 39: 412-423$.

471 Federal Interagency Forum on Aging-Related Statistics. 2004. Older Americans 2004:

$472 \quad$ Key Indicators of Well-Being. Washington (DC) US Government Printing Office.

473 Gibbs JC, McArthur C, Milligan J, Clemson L, Lee L, Boscart VM, Heckman G, Rojas-

474 Fenandez C, Stolee P, and Giangregorio LM. 2015. Measuring the

475 implementation of a group-based Lifestyle integrated Functional Exercise (Mi-

476 LiFE) intervention delivered in primary care for older adults aged 75 years or

477 older: a pilot feasibility study protocol. Pilot and Feasibility Studies 1.

478 Hairi NN, Cumming. RG, Naganathan V, Handelsman DJ, Le Couteur DG, and Creasey

479 H. 2010. Loss of muscle strength, mass (sarcopenia), and quality (specific force)

480 and its relationship with functional limitation and physical disability: the concord

481 health and ageing in men project Journal of the American Geriatrics Society

$482 \quad 58: 2055-2062$.

483 Hassan BH, Hewitt J, Keogh JWL, Bermeo S, Duque G, and Henwood TR. in press.

$484 \quad$ Impact of resistance training on sarcopenia in nursing care facilities: a pilot study. $485 \quad$ Geriatric Nursing. 
486 Henwood T, Keogh J, Reid N, Jordan W, and Senior H. 2014. Assessing sarcopenic 487 prevalence and risk factors in residential aged care: methodology and feasibility. $488 \quad$ Journal of Cachexia, Sarcopenia and Muscle 5:229-236.

489 Henwood T, Neville C, Baguley C, Clifton K, and Beattie E. 2015. Physical and functional 490 implications of aquatic exercise for nursing home residents with dementia $491 \quad$ Geriatric Nursing 36:35-39.

492 Henwood T, Wooding A, and de Souza D. 2013. Center-Based Exercise Delivery. 493 Feasibility of a staff-delivered program and the benefits for low-functioning older 494 adults accessing respite day care Activities, Adaptation \& Aging 37:224-238. 495 Justine M, Hamid TA, Mohan V, and Jagannathan M. 2012. Effects of multicomponent exercise training on physical functioning among institutionalized elderly. ISRN Rehabilitation.

Kalinowski S, Wulff I, Kölzsch M, Kopke K, Kreutz R, and Dräger D. 2012. Physical activity in nursing homes--barriers and facilitators: a cross-sectional study. Journal of Aging and Physical Activity 20:421-441.

501 Keogh JW, Senior H, Beller EM, and Henwood T. 2015. Prevalence and risk factors for $502 \quad$ low habitual walking speed in nursing home residents: an observational study. Archives of Physical Medicine and Rehabilitation 96:1993-1999.

504 Kressig RW, Gregor RJ, Oliver A, Waddell D, Smith W, O-Grady M, Curns AT, Kutner M, 505 and Wolf SL. 2004. Temporal and spatial features of gait in older adults transitioning to frailty. Gait and Posture 20:30-35.

507 Krist L, Dimeo F, and Keil T. 2013. Can progressive resistance training twice a week 508 improve mobility, muscle strength, and quality of life in very elderly nursing-home 509 residents with impaired mobility? A pilot study. Clinical Interventions in Aging $510 \quad 8: 443-448$. 
511 Kuys SS, Peel NM, Klein K, Slater A, and Hubbard RE. 2014. Gait speed in ambulant

512 older people in long term care: a systematic review and meta-analysis. Journal of 513 the American Medical Directors Association 15:194-200.

514 Mathiowetz V. 2002. Comparison of Rolyan and Jamar dynamometers for measuring 515 grip strength. Occupational Therapy International 9:201-209.

516 McDonough AL, Batavia M, Chen FC, Kwon S, and Ziai J. 2001. The validity and 517 reliability of the GAITRite system's measurements: A preliminary evaluation.

518 Archives of Physical Medicine and Rehabilitation 82:419-425.

$519 \quad$ 10.1053/apmr.2001.19778

520 Millor N, Lecumberri P, Gomez M, and Martinez-Ramirez A, Izquierdo, M. 2013. An

521 evaluation of the 30-s chair stand test in older adults: frailty detection based on

522 kinematic parameters from a single inertial unit Journal of NeuroEngineering and

523 Rehabilitation 10.

524 Onder G, Pennic BWJH, Lapuerta P, Fried LP, Ostir GV, Guralnik JM, and Pahor M.

525 2002. Change in physical performance over time in older women: the Women's

526 Health and Aging Study. Journals of Gerontology Series A: Biological Sciences

527 and Medical Sciences 57:M289-293.

528 Peddle-Mclntyre CJ, Bell G, Fenton D, McCargar L, and Courneya KS. 2012. Feasability 529 and preliminary efficacy of progressive resistance exercise training in lung cancer $530 \quad$ survivors. Lung Cancer 75:126-132.

531 Peel NM, Kuys SS, and Klein K. 2013. Gait speed as a measure in geriatric assessment 532 in clinical settings: a systematic review. Journal of Gerontology Series A:

533 Biological Sciences and Medical Sciences 68:39-46. 10.1093/gerona/gls174

534 Reid N, Eakin E, Henwood T, Keogh JWL, Senior HE, Gardiner PA, Winkler E, and 535 Healy GN. 2013. Objectively measured activity patterns among adults in 

Health 10:6783-6798.

538 Roberts HC, Denison HJ, Martin HJ, Patel HP, Syddall H, and Cooper C. 2011. A review 539 of the measurement of grip strength in clinical and epidemiological studies:

$540 \quad$ towards a standardised approach. Age Ageing 40:423-429.

541 Sabol VK, Resnick B, Galik E, Gruber-Baldini AL, Morton PG, and Hicks GE. 2011.

542 Exploring the factors that influence functional performance among nursing home 543 residents. Journal of Aging Health 23:112-134.

544 Senior HE, Henwood TR, Beller EM, Mitchell GK, and Keogh JWL. 2015. Prevalence 545 and risk factors of sarcopenia among adults living in nursing homes. Maturitas

547 Sievanen H, Karinkanta S, Moisio-Vilenius P, and Ripsaluoma J. 2014. Feasibility of whole-body vibration training in nursing home residents with low physical function: a pilot study Aging Clinical and Experimental Research 26:511-517.

554 Sterke CS, van Beeck EF, Loonman CWN, Kressig RW, and van der Cammen TJM. 2012. An electronic walkway can predict short-term fall risk in nursing home residents with dementia. Gait and Posture 36:95-101.

557 Suttanon P, Hill KD, Said CM, Williams SB, Byrne KN, LoGuidice D, Lautenschlager NT, 558 and Dodd KJ. 2013. Feasibility, saftey and preliminary evidence of the effectiveness of a home-based exercise programme for older people with 

27:427-438.

562 Taekema DG, Gussekloo J, Maier AB, Westendorp RGJ, and De Craen AJM. 2010.

563 Handgrip strength as a predictor of functional, psychological and social health. A

564 prospective population-based study among the oldest old. Age and Ageing $565 \quad 39: 331-337$.

566 Valenzuela T. 2012. Efficacy of progressive resistance training interventions in older 567 adults in nursing homes: a systematic review. Journal of the American Medical 568 Directors Association 13:418-428. 10.1016/j.jamda.2011.11.001

569 Zijlstra A, Mancini M, Lindemann U, Chiari L, and Zijlstra W. 2012. Sit-stand and stand570 sit transitions in older adults and patients with Parkinson's disease: event 571 detection based on motion sensors versus force plates Journal of $572 \quad$ NeuroEngineering and Rehabilitation 9:75. 


\section{Tables}

574 Table 1: Descriptive data for the residents in the exercise control and group.

\begin{tabular}{lcc}
\hline \multicolumn{1}{c}{ Variable } & Exercise Group (n = 20) & Control Group (n = 17) \\
\hline Age (yrs) & $86.9 \pm 5.7$ & $86.3 \pm 6.6$ \\
Range (yrs) & $72-97$ & $75-99$ \\
& & \\
No. of females (no.\%) & $15(75 \%)$ & $15(88 \%)$ \\
Length of stay in RAC & $745.1 \pm 622.6$ & $755.0 \pm 492.1$ \\
(days) & & $14.2 \pm 5.3$ \\
Medical Conditions (no.) & $15.3 \pm 5.2$ & $14.6 \pm 5.9$ \\
Medications (no.) & $14.3 \pm 6.1$ & $13(76 \%)$ \\
Use of walking aid & $11(55 \%)$ & $27.2 \pm 4.7$ \\
BMl (kg/m $\left.{ }^{2}\right)$ & $26.5 \pm 3.7$ & $38.8 \pm 5.6$ \\
Body fat \% & $33.2 \pm 10.8$ & \\
Marital Status & & $2(12 \%)$ \\
$\quad$ Married & $4(20 \%)$ & $0(0 \%)$ \\
$\quad$ Divorced & $3(15 \%)$ & $15(88 \%)$ \\
$\quad$ Widowed & $13(65 \%)$ &
\end{tabular}




\begin{tabular}{lcc} 
Nationality & \\
European & $20(100 \%)$ & $15(88 \%)$ \\
$\begin{array}{l}\text { Asian } \\
\text { Primary Language }\end{array}$ & 0 & $2(12 \%)$ \\
English & $19(95 \%)$ & $16(94 \%)$ \\
German & $1(5 \%)$ & $1(6 \%)$ \\
Russian & 0 & $14(82 \%)$ \\
Mini-COG status \# & $12(60 \%)$ & $3(18 \%)$ \\
Positive & $8(40 \%)$ & \\
Negative & & \\
\hline Data are mean \pm standard deviation; yrs = years; no. = number
\end{tabular}

575 Data are mean \pm standard deviation; yrs = years; no. = number 
576 Table 2: Exercise group participant questionnaire post 12-week completion.

\section{Question}

Prior to commencing the exercise programme did you have any concern(s) with the GrACE programme?

$$
\begin{array}{llll}
\mathrm{SA}=0 & \mathrm{~A}=0 \quad \mathrm{U}=1 \quad \mathrm{D}=15 & \mathrm{SD}=4
\end{array}
$$

Did you have any concern(s) with the GrACE programme upon completing the exercise programme?

$$
\begin{array}{lllll}
S A=2 & A=18 & U=0 & D=0 & S D=0
\end{array}
$$

Did you enjoy participating in the GrACE programme?

$$
\begin{array}{lllll}
S A=20 & A=0 & U=0 & D=0 & S D=0
\end{array}
$$

Do you believe the GrACE programme was well organised?

$$
\begin{aligned}
& S A=20 \\
& A=0 \\
& \mathrm{U}=0 \\
& \mathrm{D}=0 \\
& S D=0
\end{aligned}
$$

Whilst participating in the GrACE programme do you believe that the programme impeded on your daily routine?

$$
\begin{array}{lllll}
S A=0 & A=0 & U=0 & D=17 & S D=3
\end{array}
$$

Would you be happy to continue participating in the GrACE programme or something similar?

$$
\mathrm{SA}=20 \quad \mathrm{~A}=0 \quad \mathrm{U}=0 \quad \mathrm{D}=0 \quad \mathrm{SD}=0
$$

Overall, would you rate your current physical condition to be better than before you started the GrACE programme?

$$
\mathrm{U}=0 \quad \mathrm{D}=0 \quad \mathrm{SD}=0
$$

$577 \mathrm{SA}=$ Strongly agree, $\mathrm{A}=$ Agree $\mathrm{U}=$ Unsure, $\mathrm{D}=$ Disagree, $\mathrm{SD}=$ Strongly disagree . 
578 Table 3: Changes in the muscle function outcomes for the exercise and control groups.

Muscle Exercise Group Control Group Between-

Function

group

Outcome

significan

ce

\begin{tabular}{cccccccc} 
& Pre & Post & $\begin{array}{c}\% \\
\text { Chang } \\
\text { e }\end{array}$ & Pre & Post & $\begin{array}{c}\% \\
\text { Chang } \\
\text { e }\end{array}$ & \\
\hline Gait & $0.65 \pm$ & $0.68 \pm$ & +4.6 & $0.64 \pm$ & $0.60 \pm$ & -6.0 & $0.007^{*}$ \\
speed & 0.19 & 0.17 & & 0.16 & 0.16 & & \\
(m/s) & & & & & & & \\
$\begin{array}{c}\text { Sit to } \\
\text { stand }\end{array}$ & $0.0 \pm 0.0$ & $6.4 \pm 4.5$ & NA & $0 \pm 0$ & $1.3 \pm 3.2$ & NA & $0.002^{*}$ \\
$\begin{array}{c}\text { (repetitio } \\
\text { ns) }\end{array}$ & & & & & & & \\
$\begin{array}{c}\text { Handgrip } \\
\text { strength }\end{array}$ & $15.2 \pm$ & $15.9 \pm$ & +4.6 & $13.2 \pm$ & $10.6 \pm$ & -19.7 & $0.001^{*}$ \\
(kg) & 5.3 & 5.9 & & 4.5 & 4.1 & &
\end{tabular}

579 All data were reported as mean \pm standard deviation; $\mathrm{m} / \mathrm{s}=$ metres per second; $\mathrm{kg}=$

580 kilogram. NA $=$ not applicable as the pre-test score equalled zero. ${ }^{*}=$ Statistical

581 significance $(p<0.05)$ 


\section{Figures}

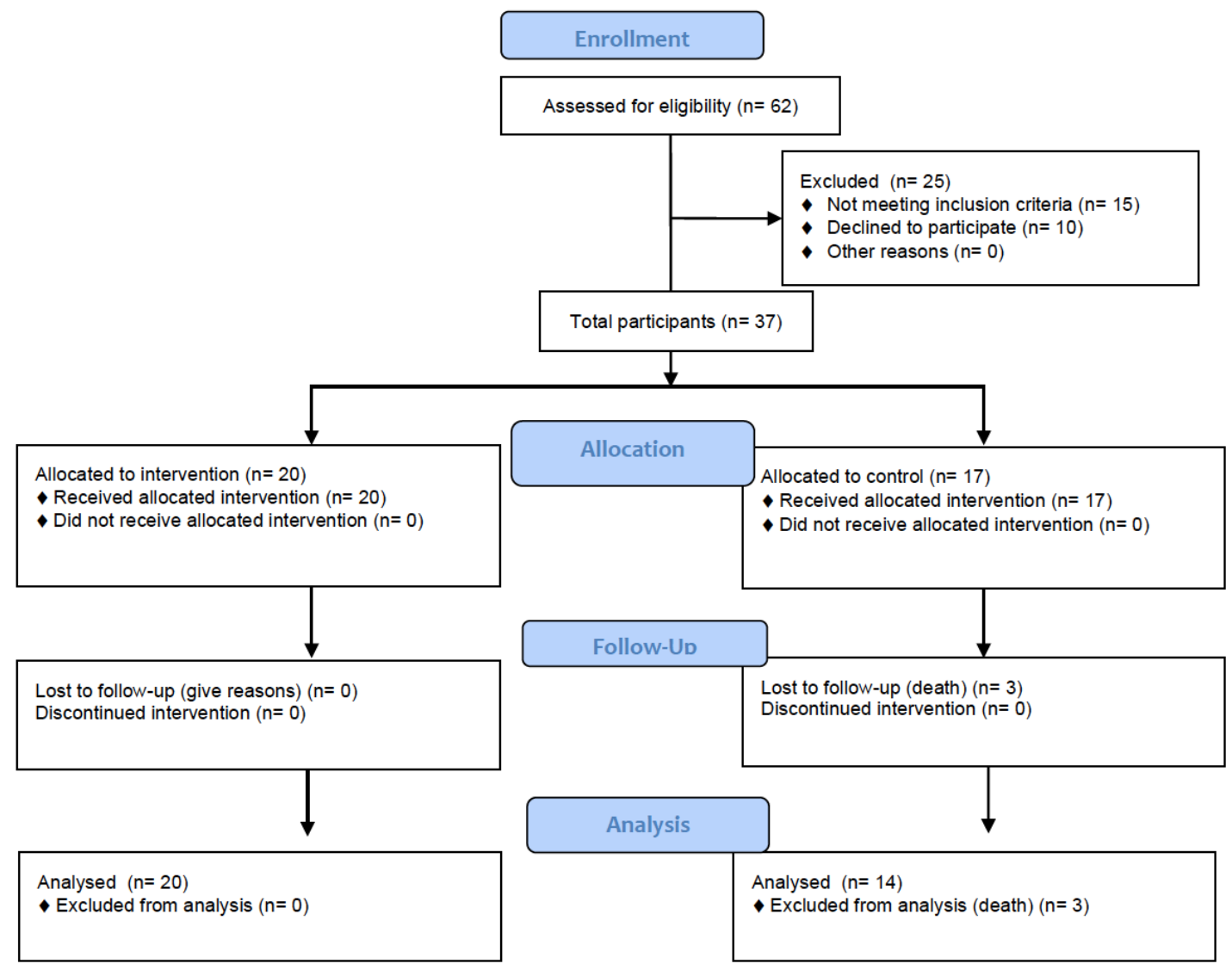

583 Figure 1. Project CONSORT diagram of recruitment and assessment of study

584 participants. Enrolment numbers and withdrawals, or those lost to follow-up, are

585 indicated in the boxes. 


\section{Appendix}

\section{Appendix 1.}

588 The GrACE Programme

589 The programme included weight-bearing exercises and a range of seated, non-resisted

590 upper- and lower-body dynamic and reaching movements. Prior to performing the 591 exercises, participants warmed up for approximately fifteen minutes using the non592 resistive movements, and completed each session with a warm down of approximately 593 ten minutes with targeted stretching. The stretches involved non-resistive movements 594 undertaken two or three times and reaching (stretching) movements were held for 20 595 seconds. Between the warm up and cool down the participants performed the following596 weight bearing and resistance exercises: chair stands, chair dips, calf raises and hip 597 flexor/abdominal lifts, trunk twists, and bicep curl and shoulder press.

598 The aim was to complete three sets of ten repetitions per exercise. Initially participants 599 worked at a reduced intensity (50\% of estimated $1 \mathrm{RM})$ and number of sets and 600 repetitions, with the sets and repetitions increasing over the first four weeks to reach the 601 GrACE programmes full delivery goal. Prior to the GrACE programme all participants 602 were familiarised to the programme, with participants commencing with no resistance so 
603 to encourage appropriate technique and posture, whilst reducing reliance on balancing

604 aids before progressing to resistance (dumbbells).

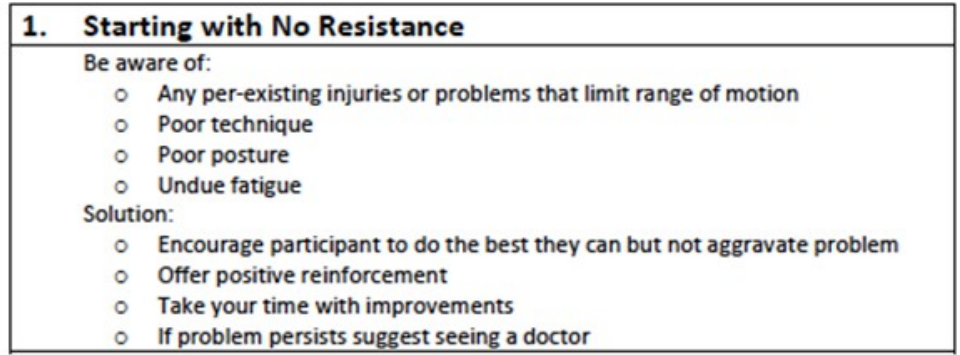

- If problem persists suggest seeing a doctor

\begin{tabular}{|l|l|}
\hline $\begin{array}{l}\text { Has the participant achieved } \\
\mathbf{3} \text { sets of } 10 \text { repetitions } \\
\text { using } \\
\text { GOOD TECHNIQUE AND POSTURE? }\end{array}$ & $\begin{array}{l}\text { KEEP GOING AT THE SAME } \\
\text { INTENSITY }\end{array}$ \\
\hline
\end{tabular}

2. Increasing the time in the down phase

For example:

- Chair Stands Sitting down as slowly as possible

- Chair Dips Lowering down slowly as possible

- Calf/Knee Raises Dropping the feet back to the ground as

slowly as possible

- Trunk Twists Rotating the trunk as slowly as possible

- Bicep Curl/Shoulder Press Return the hand (dumbbells) slowly to shoulder then to the waist

\begin{tabular}{|l|l|}
\hline $\begin{array}{l}\text { Has the participant achieved } \\
\mathbf{3} \text { sets of } \mathbf{1 5} \text { repetitions } \\
\text { using }\end{array}$ & If not \\
GOOD TECHNIQUE AND POSTURE? & $\begin{array}{l}\text { KEEP GOING AT THE SAME } \\
\text { INTENSITY }\end{array}$ \\
\hline
\end{tabular}

1

3. Adding Resistance

Generally $\circ$ IF YOU INCREASE THE WEIGHT YOU DECREASE THE REPETITIONS

- IF YOU INCREASE THE REPETITIONS YOU DECREASE THE WEIGHTS

605 The programme took approximately one hour to complete and was delivered by an

606 accredited, allied health professional. Participants were closely monitored, told to rest as

607 needed and to not over exert themselves. 
608 Appendix 2

609 Feedback from the participants in regards to the exercise group

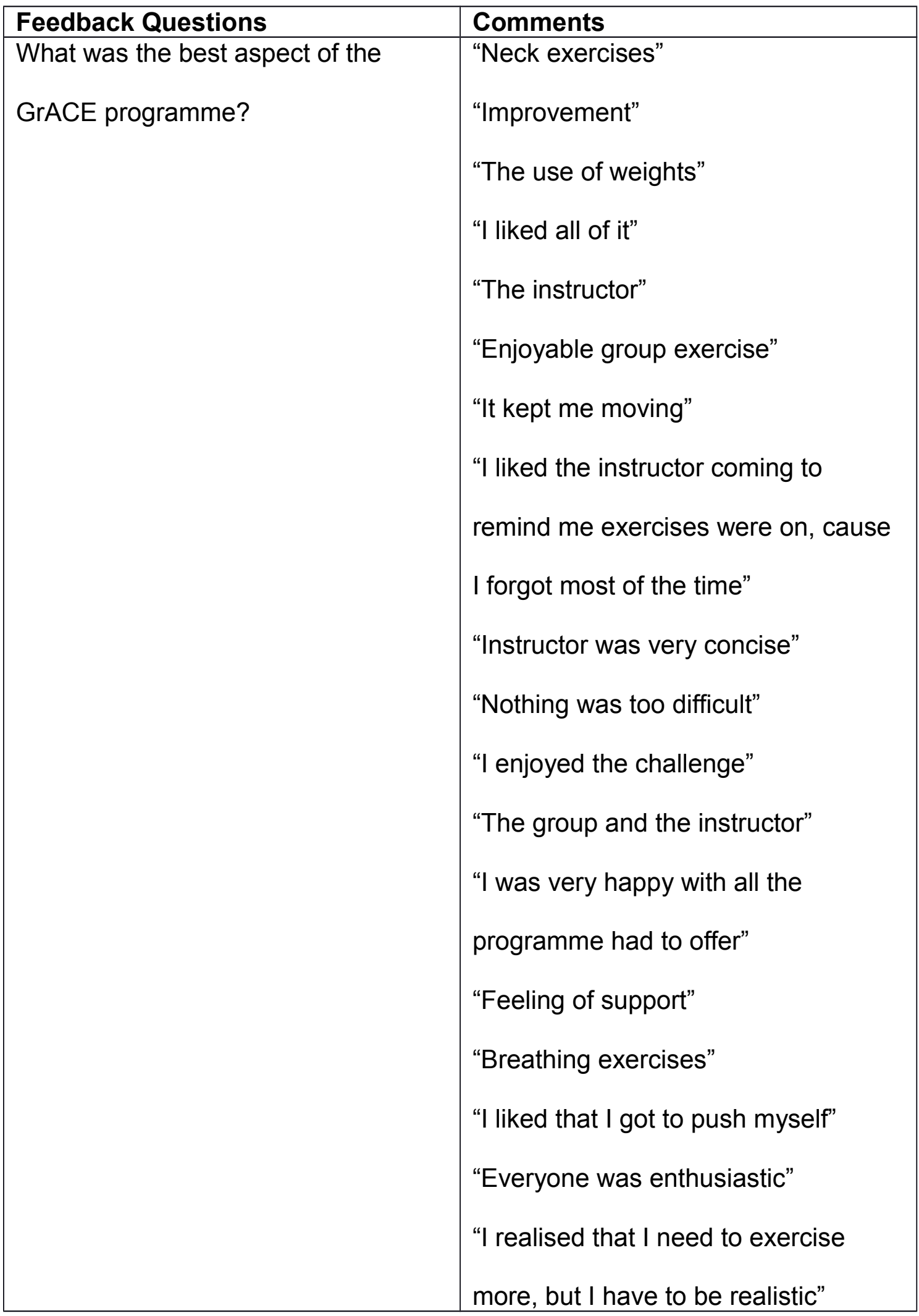




\begin{tabular}{|l|l|}
\hline What aspect of the GrACE & $\begin{array}{l}\text { "Everybody being in a group made } \\
\text { the exercises more enjoyable" }\end{array}$ \\
\hline "More time for exercises" \\
"None" \\
"Nothing" \\
"None, it was all good" \\
"I liked it all" \\
"Needs to go for longer" \\
"Better spacing of the days we do \\
exercise" \\
"I like the structure, no interruptions, \\
everyone seems to cope and it is so \\
worthwhile" \\
"Covered a lot of things that I liked" \\
"A very good, organised programme - \\
even one could say meticulous" \\
"I would like the programme to \\
continue" \\
"It was wonderful" \\
"Thank you for your organisation and \\
"I would like more variation" \\
commitment" \\
"I would like to do more of it"
\end{tabular}




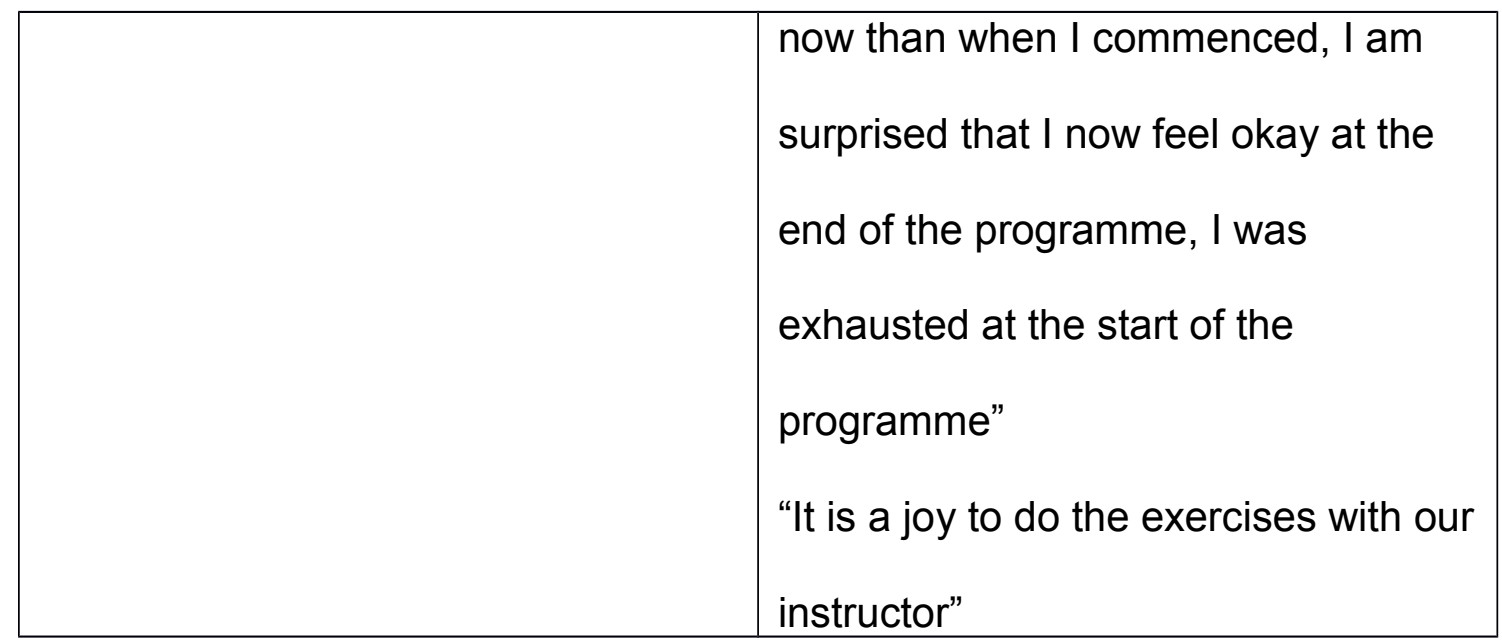

610 